\title{
Accounting for diversity and holding governments accountable: incor- porating ethnicity into local health surveys and public health surveillance systems
}

Dr. Northridge is an associated editor of this journal

While the current issue of Social and Preventive Medicine is devoted to social, ethnic, and gender diversity in survey research, the sole research paper from the United States features patterns of body weight in middle-aged and older Americans by gender and race only (Jenkins et al. 2003). This is perhaps not surprising, as racism has been the primary form of group oppression in the United States since its founding over 200 years ago, and race relations continue to permeate virtually every aspect of U.S. life, including health and well being (Cohen \& Northridge 2000).

In "The condition of the working class in England" first published in 1845, Friedrich Engels noted the poor health and mortality record of the Irish living in England (Engels 2000). Contemporary research in Britain has found that adjustment for social class fails to attenuate the adult mortality differential observed according to place of birth (Davey Smith 2000). And while mortality data are not routinely published by race in South Africa and Zimbabwe - two multiracial societies that dismantled legal discrimination established during the colonial period late in the $20^{\text {th }}$ centurywhat data are available show a disproportionate share of black compared to white mortality, and a recent widening of the racial gap due to the growing impoverishment of Blacks, including the devastating toll of AIDS-related mortality (Bassett 2000).

Today, data on race and ethnicity are routinely collected in virtually all local health surveys and public health surveillance systems in the United States, to both characterize communities demographically, and to monitor racial/ethnic disparities in population health. Missing are reliable measures of social class, although ongoing efforts to incorporate areabased socio-economic measures derived from the U.S. decennial census into public health surveillance systems hold promise for monitoring, even as they are limited for conducting etiologic research (Krieger et al. 2002).

Below I discuss ethnicity with regard to the two main goals of Social and Preventive Medicine, namely: (1) informing public health surveillance systems to better monitor progress and setbacks over time and across populations in eliminating inequalities in health [including by ethnicity]; and (2) publishing data from local health surveys that are collected to inform local programs and target interventions for diverse [ethnic] subgroups.

\section{Holding governments accountable}

Since 1790, the U.S. government has been collecting - and changing each decade the way it collects - data on race and ethnicity that provide denominators for social and demographic analyses (Wallman et al. 2000). The intended goal is to account for the increasing diversity in the United States, while maintaining the ability to measure and track social and economic conditions for populations that historically have experienced discrimination. The U.S. Office of Management and Budget $(O M B)$ published the following revisions to the standards for the classification of federal data on race and ethnicity in 1997 (www.whitehouse.org):

The categories in this classification are social-political constructs and should not be interpreted as being scientific or anthropological in nature... The revised standards will have five minimum categories for data on race: American Indian or Alaska Native, Asian, Black or African American, Native Hawaiian or Other Pacific Islander, and White. There will be two categories for data on ethnicity: "Hispanic or Latino" and "Not Hispanic or Latino.”

Soz.- Präventivmed. 48 (2003) 211-213 
In addition to employing new categories of race/ethnicity, the option to select multiple categories of race signaled a major shift in the conceptualization of race/ethnicity in the United States, with important implications for monitoring racial/ethnic inequalities in health, and allocating resources relevant to population health (Krieger 2000).

\section{Accounting for diversity}

Which - if any - measures of ethnicity are incorporated into local health surveys depends upon the purpose of a given survey, who lives in the community, when the survey is conducted, and how the findings will be compared to other surveys. For instance, we are conducting an asthma screening survey in Central Harlem, New York City for children aged 0-12 that we first reported on in Social and Preventive Medicine (Northridge et al. 2002). The purpose of this screening survey is to identify children with asthma in order to enroll them in a comprehensive intervention program that offers an array of environmental, educational, social, and medical services. While the large majority of enrolled participants are African, American, and Caribbean Blacks, there is diversity within this group in terms of language(s) spoken at home, years lived in the United States, and health insurance eligibility and coverage. Hence, in order to best serve enrolled children and their families, detailed information on racelethnicity is desired. Further, in order to compare the prevalence of asthma with findings from other U.S. surveys, it was deemed essential to adhere to the 1997 revised U.S. OMB standards for race and ethnicity (www.whitehouse.org). Accordingly, data are being collected on each child's Spanish/Hispanic/Latino ethnicity (Puerto Rican, Mexican/Mexican American/Chicano, Dominican, and other Spanish/Hispanic/Latino - group specified) and race (Black/African American, White, Asian, American Indian/Alaska native - enrolled or principle tribe specified). Also consistent with the Year 2000 U.S. census, respondents are instructed to "mark one or more races to indicate what you consider your child to be." In addition, respondents are asked, "Where was your child born?" (The listed categories include the United States, the Dominican Republic, West Africa, Puerto Rico, the West Indies, and other-specified.) The screening form was translated into Spanish from English due to increasing numbers of migrants from Latin America in Central Harlem, although there is also a need for translation into French to accommodate recent migrants from West Africa and the West Indies.

\section{Colorful communities}

In her lead editorial for the April 2002 issue of the American Journal of Public Health devoted to women of color, Gabriel Stover argued that there remains the need for both a collective voice for women who remain underrepresented, and a language to describe them (Stover 2002). In the May 2003 issue of the American Journal of Public Health dedicated to men's health, Henrie Treadwell and Marguerite Ro bemoaned the fact that virtually no health efforts are directed towards poor men of color, who have become "invisible" (Treadwell \& Ro 2003). Clearly, there is much to be done in sorting out the complexities inherent in social, ethnic, and gender survey research. As committed and engaged researchers, we have much to contribute towards both accounting for the ethnic diversity in our communities, and holding our governments accountable for eliminating disparities in health by social class, ethnicity, and gender.

Mary E. Northridge

\section{Acknowledgment}

Financial and ongoing program support for Dr. Northridge is provided by the Centers for Disease Control and Prevention through the Harlem Health Promotion Center, and the Robin Hood Foundation and Anne E. Dyson Community Pediatrics Training Initiative through the Harlem Children's Zone Asthma Initiative. 


\section{References}

Bassett MT (2000). The pursuit of equity in health: reflections on race and public health data in Southern Africa. Am J Public Health 90: 1690-3.

Cohen HW, Northridge ME (2000). Getting political: racism and public health. Am J Public Health 90: 841-2.

Davey Smith G (2000). Learning to live with complexity: ethnicity, socioeconomic position, and health in Britain and the United States. Am J Public Health 90: 1694-8.

Engels $F$ (2000). The condition of the working class in England. Harmondsworth: Penguin. (Originally publ. 1845). In: Davey Smith G. Learning to live with complexity: ethnicity, socioeconomic position, and health in Britain and the United States. Am J Public Health 90: 1694-8.
Jenkins KR, Fultz NH, Fonda SJ, Wray LA (2003). Patterns of body weight in middle-aged and older Americans, by gender and race, 1993-2000. Soz Praventiv Med 48: 257-68.

Krieger $N$ (2000). Counting accountably: implications of the new approaches to classifying race/ethnicity in the 2000 census. Am J Public Health 90: 1687-9.

Krieger N, Chen JT, Waterman PD, Soobader MJ, Subramanian SV, Carson R (2002). Geocoding and monitoring of US socioeconomic inequalities in mortality and cancer incidence: does the choice of area-based measure and geographic level matter? The Public Health Disparities Geocoding Project. Am J Epidemiol 156: 471-82.

Northridge ME, Jean-Louis B, Shoemaker K, Nicholas $S$ (2002). Advancing population health in the Harlem Children's Zone Project. Soz Praventiv Med 47: 201-4.

Stover GN (2002). Colorful communities: toward a language of inclusion. Am J Public Health 92: 512-4.
Treadwell HM, Ro M (2003). Poverty, race, and the invisible men. Am J Public Health 93: 705-7.

Wallman KK, Evinger S, Schechter S (2000). Measuring our nation's diversity: developing a common language for data on race/ethnicity. Am J Public Health 11: 1704-8. http://www.whitehouse.gov/omb/fedreg/ombdir15.html. (Accessed May 5, 2003).

Address for correspondence

Mary E. Northridge, PhD, MPH Associate Professor of Sociomedical Sciences

Mailman School of Public Health

Columbia University

USA-New York, NY 10032

Tel.: + 1-212-342-2313

Fax: +1-212-342-2320

e-mail:men11@columbia.edu 